\title{
A Brief Analysis of Enhancing the Management of Language Lab
}

\author{
Run Hua Wu ${ }^{1}$, Jian Jun Shi ${ }^{2}$ \\ ${ }^{1}$ College of Foreign Language, North China University of Science and Technology, Beijing-east Yanjiao, China \\ ${ }^{2}$ Safety Engineering College North China University of Science and Technology Beijing-east Yanjiao, China \\ shjjwrh@126.com
}

\begin{abstract}
With the development of technology, language lab begins to perform a vital role in foreign language teaching. This paper presents the necessity of enhancing the management of language lab. Based on some problems in present situation of management, this paper proposes some management methods from views of student management, system utilization and the repairs and maintenance of language lab.
\end{abstract}

Index Terms - language lab, problems, management, quality

\section{Introduction}

With the increasing international intercourse and development of multimedia, modern educational technologies are widely used in foreign language teaching. The teaching method of visual-audio-oral has entered a new stage in China. The weight of listening and speaking is increasing in college English teaching. Multimedia language lab begins to play an important role in teaching assistance.

Multimedia language lab has become one of the fundamental facilities in colleges. Language lab is a product of high technology. It can create clear phonetic environments with excellent fidelity. The equipments with perfect functions and stable quality are the guarantee of the good teaching performance in language lab. The management of multi-media language lab will directly affect its' assistant teaching result [1-5].

\section{The Role of Multi-media Language Lab in Foreign Language Teaching}

The biggest advantage of language lab is it can increase the students' language practice opportunities. Students can get more autonomy in the study. It's characterized by interactive mode and individualized teaching. As foreign language is a difficult subject for most students, it's hard to improve the listening and speaking skills. Language lab provides possibilities to improve these skills[6].

A. Improving the Efficiency of Classroom Teaching, Increasing the Students' Practice Opportunities.

In the language lab teaching, the whole students in the class can focus on the language learning and don't disturb each other. When the teacher is giving individual attention to someone, the others don't have to wait passively. All the students can stay positive and focused, so their learning efficiency will be improved greatly.
B. Encouraging the Teachers to Improve Teaching Methods. The utilization of modern teaching means in language lab has expanded the teaching content significantly. Objectively, the teachers should change the teaching method accordingly. The utilization of language lab reflects the modernization of education. It will change traditional teaching thoughts and reform teaching methods.

\section{Create Excellent Language Environments.}

Any language is best learnt through a process of immersion. The real context is a shortcut to foreign language learning, but it's also hard to establish a pure foreign language environment. Language lab is a kind of modern teaching facilities. It creates a simulated environment using slide projector, television, video, film and so on. In foreign language lab, students can imitate the pronunciation and intonation. At the same time, they can understand the words and sentences better. A good language environment will improve students' initiative and creativity to get a better result.

D. Teaching Students In Accordance of Their Aptitude and Giving Individual Tutorial.

Although the students study together in the same language lab, they can have different pace and progress. The teachers can add a few set of textbooks to provide teaching materials of different difficulties. Then the students can make the content selection in accordance of their aptitude. So the students have autonomy to decide their learning progress. At the same time, the students can contact teachers for help when they encounter problems. Teaching students in accordance of their aptitude and giving individual tutorial can activate students' learning enthusiasm effectively.

\section{The Necessity of Scientific Management of language lab}

From simple single-media with few functions to high-tech multi-media with many features, language teaching equipments are constantly upgraded. On the one hand, the rapid change of high technology requires the administrative staff to renew their knowledge and management skills. On the other hand, the scientific progress has promoted the modernization process of education. Language teaching equipments have been widely used in language teaching. The management should be raised to a new level for meeting the demands of modern high-tech language teaching mode, both in scope and in depth. Therefore, it's essential to strengthen management awareness 
of administrative staff, adopt scientific management methods and improve management level.

\section{The Problems in the Management of Language Lab}

\section{A. It's Hard to Maintain the Environment of Lab.}

Recently, most students can get in and out of the language lab with dust freely. The situation gets worse in bad weather. Some students even ignore and rules of lab and bring food or water into the lab. All these factors make it difficult to maintain the environment of lab.

\section{B. There Are Serious Disruptive Behaviors Existing In the Language Lab.}

The students lack self-control because of age. The teachers can't observe their behaviors at any time when they are in language lab. So the teachers don't know whether they are studying following the directions exactly. Some students plug the hardware arbitrarily, install unsafe software and modify system or CMOS configurations. Some of them play computer games, watch movies or chat online in class. Moreover, they snip the wires, break the earphones and steal the computer parts.

\section{The Work of Lab Is Onerous, So Lab Personnel Are Under Heavy Work Load.}

Automation has not been introduced in the management of language lab recently. Lots of repetitive work still needs to be finished manually. So the teachers of lab are under heavy work load. Some foreign language teachers don't have good computer operation skills and they just use a particular medium. It's hard to get the optimal combination to take advantage of language lab. Some teachers get accustomed to using the traditional teaching mode due to a lack of right awareness of modern education technology. They don't want to spend time and energy in mastering new technology of multi-media language lab.

\section{Enhancing the Management of Language Lab}

Whether the language lab can maximize its effectiveness or not depends to a great extent on the management. Here are a few ways to manage the language lab scientifically and effectively.

\section{A. Establishing Right Concept of Management.}

Firstly, the administrative staff of language lab should define the services target, working target and realistic problems in working clearly. They should be able to propose solutions to solve the problems. At the same time, they should have professional ethics and dedication with good sense of responsibility and service. Professional skills, expertise in management, educational technology and organizational behavioral science, and great ability of management, coordination and communication are basic requirements for managing language lab. Only in that way, the colleges can take full advantage of language lab and improve the quality and efficiency of education.

\section{B. Improving the Rules and Regulations and Promoting the Development Language Lab.}

The management of language includes equipment management, document management, environment management and usage management. In other words, the administrative staff should not only maintain and repair the devices of voice system, but also strengthen the supervision and checking of users' operation. For the guarantee of normal usage, an excellent regulatory system should be established in the language lab. Strengthen the supervision in class and checking after class can help identify problems and take care of any issues effectively. A perfect management system should include the rules on the use of language lab for teachers, the rules on the use of language lab for students, safety regulations of language lab and so on. In addition, records of the using of equipments, violation records and bulletin board should be established as supplementary contents. Simple punishment can't solve the underlying problems. The administrative staff should make sufficient investigation to find out where the problem is and what the liabilities are. The students sign the violation records after they have realized the harm of their behaviors. Lastly, a notice of criticism on bulletin board is taken as a warning for other students.

\section{Enhancing the Management of Equipments.}

Language lab has many functions which are not utilized to the best advantage. Some functions are under low use rate and a few of them are rarely used. Most teachers just use a few simple functions like voice communication. Some teachers even use the voice devices as tape recorders. To increase the value of language lab, the teachers need to get proper training in theoretical knowledge and practical operations before they use the lab in class. And administrative staff of lab should be able to troubleshoot the common problems and ensure the class goes on well.

\section{Improving the Professional Skills of Lab Teachers.}

Modern education technology training for teachers is a key part of the management of language lab. The coexistence of listening and reading classroom, multi-media language lab and digital voice lab makes the teaching location is not fixed. So the teachers must master operation skills of different voice equipments. At the beginning of each semester, it is very necessary to train the teachers in comprehensive modern education technology and methods. The training will help them improve the quality of education. And the teachers also can turn to supporting operation manual of equipments or administrative staff, if they have some forgotten or unfamiliar operations.

\section{E. Strengthening Quality Education on Students.}

Students are asked to keep records of the using of equipments. The records make it easy to trace the cause of equipment failure and find the relevant people. If the failure is caused by human factors, the person responsible will be blamed. The teachers should keep records of the using of language lab seriously after class. Then the administrative staff can stay informed of equipments' working condition. So they 
can solve the problems timely and make sure the devices are working properly.

\section{F. Improving Personal Qualities of Lab Personnel Is the Key} to Scientific Management.

Administrative staff should improve scientific accomplishment and insist on a practical and realistic way of doing things. To cultivate the qualified administrative staff, it's necessary to create the learning organization environment, which means the combination of self-learning and training, theory and operating skills, attendance and performance. The qualified administrative staff able to work independently can take full advantage of devices and provide a reliable guarantee for improving the teaching quality.

\section{Acknowledgment}

The management of multimedia language lab is a complicated work. We need to pay attention to the effects of language lab on foreign language teaching and get familiar with the development of language lab, when constructing and managing the college language lab. Furthermore, we should develop and maintain the functions of language lab positively for its long-term development. Enhancing the management can contribute to utilizing the functions and advantages of language lab, improving the quality and efficiency of teaching and promoting the modernization process of education.
The work was financially supported by the Research project of North China institute of science and technology in 2013(Instrctional) (HKJYZD201301), The research on the practical teaching reform of mining engineering based on the connotative development.

This work was financially supported by the Funda-mental Research Funds for the Central Universities (3142013100);

Funded by the North China institute of science and technology's teaching and research projects (hkjyzd201203), the research on the practical teaching reform of mining engineering for excellent engineers.

\section{References}

[1] Wang W F, The management of language laboratory and quality-oriented education for college students. Economic research guide, 2003.

[2] Liu H H, The management of multi-media language laboratory. Science \& Technology information, vol.27, 2007, pp.476.

[3] Li W D, Zhang Y, The scientific management of multi-media language lab in colleges, Journal of Liaoning education administration institute, vol. 23(10),2006, pp.47.

[4] Jia B G, The building and managemnet of language laboratory. Jounal of Heilongjiang vocational institute of ecological engineering, vol.20 (4), 2007, pp.85-86.

[5] Tian YX, Liu ZL, The discussion of teaching and management of language lab. China modern education equipment, vol.8, 2006, pp.8-9.

[6] Qiu L Y, Chen Y L, The scientific management and maintenance of language laboratory. Education science \& Culture magazine, 2007, pp.84-84. 